\title{
Fast, furious and focused approach to Covid-19 response: an examination of the financial and business resilience of the UAE logistics industry
}

\author{
Balan Sundarakani ${ }^{1} \cdot$ Okey Peter Onyia ${ }^{1}$
}

Received: 14 June 2021 / Revised: 19 September 2021 / Accepted: 20 September 2021 / Published online: 27 October 2021

(c) The Author(s), under exclusive licence to Springer Nature Limited 2021

\begin{abstract}
While many other countries around the world were struggling to mitigate the immense health and economic effects of the global Covid-19 pandemic, the UAE Government ensured that no shortage of the supplies of goods and services affected the country. This has been attributed to the government's robust financial support to the supply chain and logistics industry during the pandemic (Atayah et al. 2021). The UAE imports over $90 \%$ of its commodities from overseas-including foods, drinks, pharmaceuticals, automobiles, clothing, electronics, building materials, logs, paper, plants, machinery, tools, and raw materials. All these products pass through the operations of the country's supply chain industry, which depends heavily on the financial institutions. Due to the above assertion, we found it necessary to empirically examine the challenges, threats and successes of the country's supply chain operators in order to ascertain their financial and business resilience during the pandemic based on the survival strategies and financial resources they received and employed during the unrelenting pandemic. Accordingly, this research has examined the financial and operational resilience of the country's supply chain organizations as reflected in their ability to maintain efficient financial strategies and stable business operations despite the scourging pandemic. Our initial findings indicate that Covid-19 pandemic interruptions on the nationwide distribution of goods and services in the UAE have been very minimal due to the government's robust financial support to the logistics industry, and consequently the business resilience developed by the industry operators.
\end{abstract}

Keywords Covid-19 pandemic · Financial resilience $\cdot$ Business resilience $\cdot$ Financial bailout $\cdot$ Emergency response strategies $\cdot$ Supply chain and logistics operations

\section{Introduction}

Catastrophes or tragedies are unavoidable elements of human history (Haddow et al. 2008). Developed countries and international organizations are usually proactive in formulating strategies and taking initiatives to forestall or contain fatalities and economic effects of emergencies such as natural disasters, epidemics, and pandemics. (Perrow 2007). Handling the aftermath of such catastrophic events is very challenging for every government; and so ineffective or lack

Balan Sundarakani

balansundarakani@uowdubai.ac.ae

Okey Peter Onyia

OkeyPeterOnyia@uowdubai.ac.ae

1 Faculty of Business, University of Wollongong in Dubai, Knowledge Park, Dubai, UAE of mitigation strategies by government agencies can cause grave disruptions in economic activities, financial services, business operations, and healthcare delivery. It is true that measuring the scope and extent of the unforeseen disasters such as pandemics beforehand is a difficult task. However, government and the disaster management agencies must take adequate steps to predict impacts of such disasters and be well prepared to handle all eventualities as efficiently as possible in order to minimize the attendant social and economic disruptions (AlShamsi and Pathirage 2015).

The world has encountered numerous challenges in the past, but in the last thirty years, the issues of natural disasters, epidemics, and wars have hindered the developmental operations and economic activities in many countries. The current global pandemic, Covid-19, also nicknamed the "Black Swan Risk," has been estimated to have caused a decline of about $6.5 \%$ in the world's economic growth between 2019 and 2020. The cumulative global GDP loss 
from 2020 to 2025 has also been projected to a massive \$US35 trillion (McKibbin and Vines 2020). The financial sector is seen as the most severely affected by this global pandemic among all economic sectors.

In addition, the global logistics and supply chain industry has also received a high degree of volatility due to the demand uncertainty, supply uncertainty and distribution uncertainty associated with the Covid-19 pandemic (Ivanov and Dolgui 2020; Ivanov 2021). As a result, most firms operating in the industry need a bailout (financial assistance) and concerted strategies to cope with the many uncertainties occasioned by the Covid-19 pandemic and maintain sustainable business performance. When demand of goods and services increases, the supply needs to match the demand accordingly; and when demand drops, suppliers, manufacturers and logistics providers need to quickly stimulate the demand and thus reduce the cash outlays on the inventory assets (Houston et al. 2016). However, these responsive mechanisms have become more difficult to achieve in the global supply chain eco-system plagued by the Covid-19 pandemic (Dolgui and Ivanov 2021). Traditional cash-flow cycles between inventory turnover, account receivables, and account payables have also become dire and longer due to the disrupting uncertainties occasioned by the pandemic.

Since the pandemic started, many firms have been unable to liquidate their inventory assets, while payments have been delayed from 60 to 90 days or sometimes even up to 180 days in various countries. These unplanned disruptions in the global logistics environment are cogent problems that warrant the need for further investigation into the dynamics of applied financial resilience and business recovery strategies in the supply chain industry. The UAE provides a good research location for investigating how a national supply chain and logistics industry has been able to deal with such problems successfully. This study has therefore investigated the financial and business resilience of the country's supply chain organizations as reflected in their ability to maintain efficient financial strategies and stable business operations despite the scourging effects of the global Covid-19 pandemic.

We synthesized our research design as an extension of the "anticipatory (intervention) and coping capacities" model proposed by Barbera et al. (2017). To refine those capacities, we adopted seven (7) variables from various sources in the related literature in the development of our extended conceptual model of business and financial resilience in the face of Covid-19 pandemic disruption (see Fig. 2). The seven variables include - Government support, Financial resources (funding) availability, Technology application, Innovative value addition, Service-delivery efficiency, Customer satisfaction, and Customer retention. Detailed discussions of these variables have been presented as the deconstruction of our analytical nodes in the methodology section of this paper.

\section{Research background}

In order to overcome the turbulent healthcare and business environment occasioned by the Covid-19 pandemic in early 2020, the governments of many countries around the world, including the UAE, implemented emergency measures and policies to ensure the continued safety and economic sustenance of their citizens and residents. The UAE appears to have done a much better job in dealing with the Covid-19 disruptions compared to other countries in the Middle East, Asia and Africa regions (Atayah et al. 2021). For example, to ensure complete safety and security of the people, the UAE government imposed some drastic measures such as a complete lockdown of the entire country and temporary cessation of all inbound and outbound flights in the country during the first half of 2020. It was an emergency situation efficiently managed by the country's National Emergency Crisis and Disaster Management Authority (NCEMA 2019). Established on May 14, 2007, based on Federal Law No.2 (2011), the NCEMA is directly supervised by the UAE Government's central administration. The organization is charged with efficiently handling all emergency and disaster situations in the country. Given that NCEMA was formed as a result of the UAE Government's determination to provide safety and security to all citizens, residents and structural assets of the country, the Government ensures that its staff are regularly trained by efficient emergency management organizations from the USA and UK (Alteneiji et al. 2021).

According to a recent study published by the Dubai Future Foundation (2020), the prompt coordinating actions of NCEMA, the Ministry of Economy, and the Ministry of Transport helped to avert the grave disruptions that the Covid-19 pandemic would have caused in the logistics and supply chain sector of the country's economy. However, significant medium-to-long-term economic risks remain to be fully addressed, especially in helping various other industries in the country to bounce back to their pre-Covid years. This situation is not peculiar to the UAE alone because the pandemic has already strained the 2020-2021 global economy with a staggering financial loss estimated to the tune of $\$ 5.5$ trillion (MEED 2020). During the lockdown months in 2020, while very many supermarketshelves in most developed economies were empty without stock, the situation in the UAE was very well managed by the UAE supply chain industry with full stock of consumer goods in all the stores around the country (Gulfnews 2020a). No store in the UAE ran out of goods even for a minute. The swift actions of the Government and logistics 
industry leaders have helped to avert any bullwhip-effect in the system (Gulfnews 2017, 2002b). Nonetheless, given the continued challenges occasioned by the protraction of the global pandemic, which has lasted more than a year now, it is necessary to examine all the existing and potential recovery strategies that have helped or would help the UAE supply chain industry to continue coping with the economic impacts of Covid-19 until full recovery is attained (Gulfnews 2020a).

\section{Literature review}

Many researchers have attempted to describe the term "disaster." According to McEntire (2015), a disaster is unpredictable situation that occurs when a deadly mass-hazard confronts human beings. Shaluf (2007) also delineates a disaster as a social calamity that causes sickness and/or death as well as economic damages. Based on the above two characterizations, it can be seen that the impact of a disaster is usually two-pronged. One is the possible harmful impact on the health and lives of the affected human beings, while the other is the damaging impact on the economy of the place where the disaster has hit.

Disasters may also be man-made or natural disasters. Examples of the two categories of disaster can be deduced from the above two scholarly definitions. Firstly, a wildfire disaster (in the bush) or a domestic-fire disaster (in buildings) can be linked to McEntire's (2015) definition, and is often advertently or inadvertently ignited by human beings. Secondly, a tornado, a tsunami, an earthquake, a volcanic eruption, or an epidemic/pandemic such as the current Covid-19 pandemic can be associated with Shaluf's (2007) definition. These are, in most cases, natural calamities. This second category corresponds to the WHO's depiction of disasters as catastrophes that cause environmental destruction, human or animal casualties, and overwhelming economic instability (Nia and Kulatunga 2017). Some other terms used interchangeably with disaster are "emergency," "crisis," "catastrophe," "devastation," and "cataclysm" (Alteneiji et al. 2021). However, what really matters is that both categories are potential threats to human existence, for which every country needs to be prepared and equipped to effectively tackle the disruptive impacts of the disaster.

\section{Impact of Covid-19 pandemic on the supply chain and logistics industry}

Right from its onset in February 2020, the Covid-19 pandemic affected the global logistics and supply chain industry drastically. Most countries locked down and shut their boarders for most parts of 2020, and majority of the people worked from home throughout that year. This global disruption has forced logistics providers around the world to redefine their business model and adopt some coping and survival strategies that would enable them continue serving their global customers despite the pandemic. As explained by North et al. (2020), the pandemic has forced logistics service providers and their corporate customers to adopt drastic measures aimed at diminishing the risk of supply chain disruptions in various countries. Resellers have also had to seek alternative and back-up suppliers and logistics service providers in a desperate bid to fulfill their orders (North et al. 2020). This has led to increased competition among logistics service providers as they rushed to adopt strategies that would showcase their coping capacities.

\section{The UAE supply chain and logistics industry}

As a vital connection point between the eastern and western parts of the world, the UAE has become a leading air and sea shipment/logistics hub for the world. As a result, most of the global trading companies have opened up offices in the UAE to take advantage of the UAE's advanced logistics capabilities and bureaucratic flexibility. The UAE invested hugely in developing the logistics hub to allow businesses easily ship and store cargo in transit through the country by air or sea. Logistics and supply chain businesses in the UAE are also providing quality services to their local and international customers (Atayah et al. 2021). The UAE government made this possible by simplifying the country's import and export regulations along with providing the necessary structural and technological infrastructure. Thus, the UAE has become a great example for the world, by gearing its logistics industry toward full customer-centric participation in the global economy. Indeed, the UAE prides itself as a champion of customer service, making customers the number one priority of all service providers at all levels of the national economy.

However, due to the fact that most countries closed their boarders and travel bans were imposed in many parts of the world during the first half of 2020, logistics service providers based in various partner-countries found it extremely difficult to provide the necessary international logistics services. This led to an increase in the lead-time of cargo deliveries, difficulties of tracking and inaccuracy of cargo information, as well as limited transparency and visibility of cargo to customers in many countries (North et al. 2020). The result was a direct negative impact on the businesses of manufacturers who depend on imported raw materials, and re-sellers who depend on imported finished goods in the various countries. The end-users of the everyday goods were, in turn, hit with "out-of-stock" notices and empty shelves in most retail stores in several countries, big and small, developed and developing (Xu et al. 2020; Suresh et al. 2020; Belhadi et al. 2021). 
Since March 2020, the Covid-19 pandemic has also caused logistics service providers to limit their capacity to accept new consignment orders from both existing and new customers. As a result, fulfilling large orders in the midst of the pandemic has continued to be extremely challenging even until date, because of the high potential risk of failure to deliver. The possibility of financial loss by all parties involved has also increased dramatically, leading to a serious disruption in customer-supplier relationships (North et al. 2020). Presently, logistics service providers are still renegotiating some of their existing contracts, as they have not been able to fulfill all the pre-Covid KPIs developed before the pandemic. In some cases, it has even become unrealistic and untenable to continue the execution of the pre-Covid contracts due to high uncertainties and cargo movements disrupted by the continued lockdowns in many countries caused by the outbreaks of new variants of the Covid-19 virus (North et al. 2020; Belhadi et al. 2021).

Going forward, the logistics service providers and their customers will have to continue developing and adopting new business models that incorporate coping and recovery strategies for dealing with the risks and disruptions caused by the still ongoing Covid-19 pandemic now and in the future. "The Impact of Covid-19 on Logistics" (Twinn et al. 2020) is a study recently released by the International Finance Corporation (IFC). In it, the authors recommend that for logistics providers to retain their customers and provide successful customer service, they will have to adapt to the new business environment and develop new safety protocols for ensuring the safety of cargo and the transport personnel (Twinn et al. 2020).

The adaptive changes they make must also ensure safety in cross-border cargo movements in recognition of the new boarder protocols introduced by different countries since the global pandemic started in early 2020. These protocols by various countries have increased the costs of logistics, with new implications for service providers' cost negotiations with their customers. It is imperative to handle these new modes of operations transparently in order to maintain healthy global supplier-customer relationships. Customers of the logistics industry, being manufacturers, distributors, and retailers, must also review their own order-management strategies in order to cope with any supply disruption caused by the Covid-19 pandemic in the logistics industry.

In addition, banks and non-bank financial institutions must continue to render a helping hand by providing flexible financial resources to the logistics operators to enable them cope with, and adapt to, the uncertainty in the business environment (Atayah et al. 2021). Their financial intermediary role between the logistics providers and their corporate customers means that the financial institutions help in creating more mutually beneficial outcomes in contract negotiations and business relationships between the logistics providers and their customers. New contracts should contain contingency and risk-mitigation terms that would help all parties involved to cope with present and future crises, so as to avoid any major disruption in the supply of goods and services, and also to ensure that no stakeholder is adversely affected in the national or global logistics industry.

The UAE Government deserves international commendation for pumping additional bailout funding into the systems, which has enabled the financial institutions to speedily provide such assistance to the supply chain and logistics operators in the country. The final result has been that throughout 2020 and until date, no distributor or retailer in the country has lacked goods to sell; the store shelves have remained fully stocked; and there has not been a single "out-of-stock" notice anywhere in the country since the pandemic started.

\section{Business resilience during a major crisis such as the Covid-19 pandemic}

"Business resilience" has been conceptualized as an organization's "ability to prevent and absorb changes and regain the initial performance level after an unexpected disturbance" (Hendry et al. 2019). In the supply chain business, Soni et al. (2014: p13) explain the concept as a supply chain/ logistics company's "adaptive capability to deal with temporary disruptive events." While reviewing the business resilience strategies in the international supply chain industry, majority of the extant studies published so far focus on the different critical situations and the immediate disruptions they caused within the first half of 2020. Not many scholars were patient enough to wait and study the protracted impacts of the yet-ongoing pandemic in the supply chain and logistics industry. In contrast, this study has examined the first full year of Covid-19 and the impacts it has caused in the industry until date.

As a result of the initial rush by various scholars to publish papers on the impacts of Covid-19 global pandemic, the facts and figures regarding the economic impacts of the pandemic on the global supply chain and logistics industry have been quite scanty and not really significant. The general consensus, however, is that supply chain businesses in many countries were significantly affected by the global pandemic. Consequently, new studies to better understand the impacts of the pandemic in various countries and to discover and share novel best practices in risk-management post Covid19 remain absolutely essential (Xu et al. 2020). In exploring the lessons so far learnt from the disruptions caused by Covid-19 in various industries, existing studies focusing on manufacturing, services, and ICT industries were examined, and the vital adoption of new technologies and Industry 4.0 capabilities was prominent (Belhadi et al. 2021). While the existing studies lack depth in revealing the financial implications of applying the Industry 4.0 strategy in supply-chain 
business recovery, highlighting its potential importance in the industry is worthwhile nonetheless.

It is therefore pertinent to explore more possible business resilience strategies, based on various frameworks, which can be used for localized industrial-sector survival, recovery and development efforts. In addition, identifying various types of collaborative strategies within and between supply chain networks is significantly necessary (Azadegan and Dooley 2021). Such network collaborations can explore the incorporation of Business Continuity Management (BCM) and Supply Chain Risk Management (SCRM) initiatives (Suresh et al. 2020). As a result, many more studies are needed even to investigate the credit-risk and liquidity-risk implications of introducing such collaborative survival, recovery and development strategies that would lead to the wholesome business resilience of the supply chain and logistics industry in the face of national, regional or global catastrophes (Gornall and Strebulaev 2018).

In Table 1, this study presents a summary of some of the most recent existing studies we reviewed in the area of the business resilience in the supply chain industry in times of crisis such as the Covid-19 pandemic. We identified some gaps in these and other reviewed studies, including the following:

- The new survival, coping, and/or recovery strategies employed by the industry operators in tackling the emergency disruptions occasioned by the crises.

- The roles of government agencies in helping to mitigate the business disruptions.

- The financial bailout of the industry by the government of the specific country involved if any.

- The added-value in service efficiency resulting from the new financial and business resilience developed by the operators.

- Changes in customer satisfaction and retention levels achieved as a result of the new business and financial resilience attained in the course of tackling the crisis.

This study therefore contributes to the existing body of knowledge in the area by examining all the above gaps we found in the literature in the context of the impacts of the ongoing Covid-19 pandemic on supply chain and logistics operations in the UAE.

\section{The role of technologies in times of crisis}

Over the years, logistics service providers have had to adopt advanced technologies to facilitate their logistics management (Mathauer and Hofmann 2019). Advanced technologies allow companies to obtain and analyze desired data in order to develop and implement business strategies. Because of the availability of assorted computer-related technologies today, it is easier now to control and manage logistics right from customer sourcing, service ordering, order processing, inventory management, goods movement, down to goods and service delivery (Kamran et al. 2021). Data collection by means of these technologies plays a great role in enhancing the logistics operators' predictive and proactive capabilities in anticipating, processing and fulfilling existing and potential customers' orders (da Silveira Batista et al. 2019).

There has been a rapid rise in major technological innovations in the global logistics industry, including artificial intelligence (AI), machine learning (ML), and blockchain technologies (BT) (Younis et al. 2021; Sundarakani et al. 2021). Within the last twenty years, international logistics service providers have invested large amounts of financial resources in automating most of their processes to inject more efficiency and effectiveness in serving their customers' shipments around the world. These innovative modernizations also introduce greater visibility and security to global logistics operations (Sundarakani et al. 2019). The result is that the logistics service providers are able to provide faster, more secure and higher-quality services to their customers, thereby attaining greater competitive advantage among competitors. In their study, Mesjasz-Lech and Włodarczyk (2020) opine that "Customer knowledge management with IT application is positively related to value delivery in business model innovation through increasing knowledge accessibility for both firms and customers." This indicates that logistics companies who invest in updating their IT systems are more likely to gain greater competitive advantage by better understanding and serving their customers more efficiently and effectively (Sundarakani et al. 2019). There has also been significant development in the hardware technology, whereby electronic seal, RFID technology and robotics are now being used in handling freights more safely and efficiently.

Across the globe, the concept of digitalization or digital transformation has been evolving as a process for fusing digital technologies with already existing traditional operational methods. This is leading to a major paradigm shift in most industries (Belhadi et al. 2021; Kamran et al. 2021). Evidently, this upgrade in systems application in the industry is also helping in the development of novel business models and unprecedented rapidity in the dissemination of goods around the world. However, this swift rise in the infusion of digital technologies into the industry is also posing some big challenges, such as incompatibility of technologies across various parts of the world. Organizations need to learn how to cope with incompatible technologies in foreign countries, as well as the proper way to adapt to new disruptive technologies while trying to remain competitive in the global market (Kouvelis and Zhao 2018). Overall, the need for supply chain and logistics operators to adopt transformative 


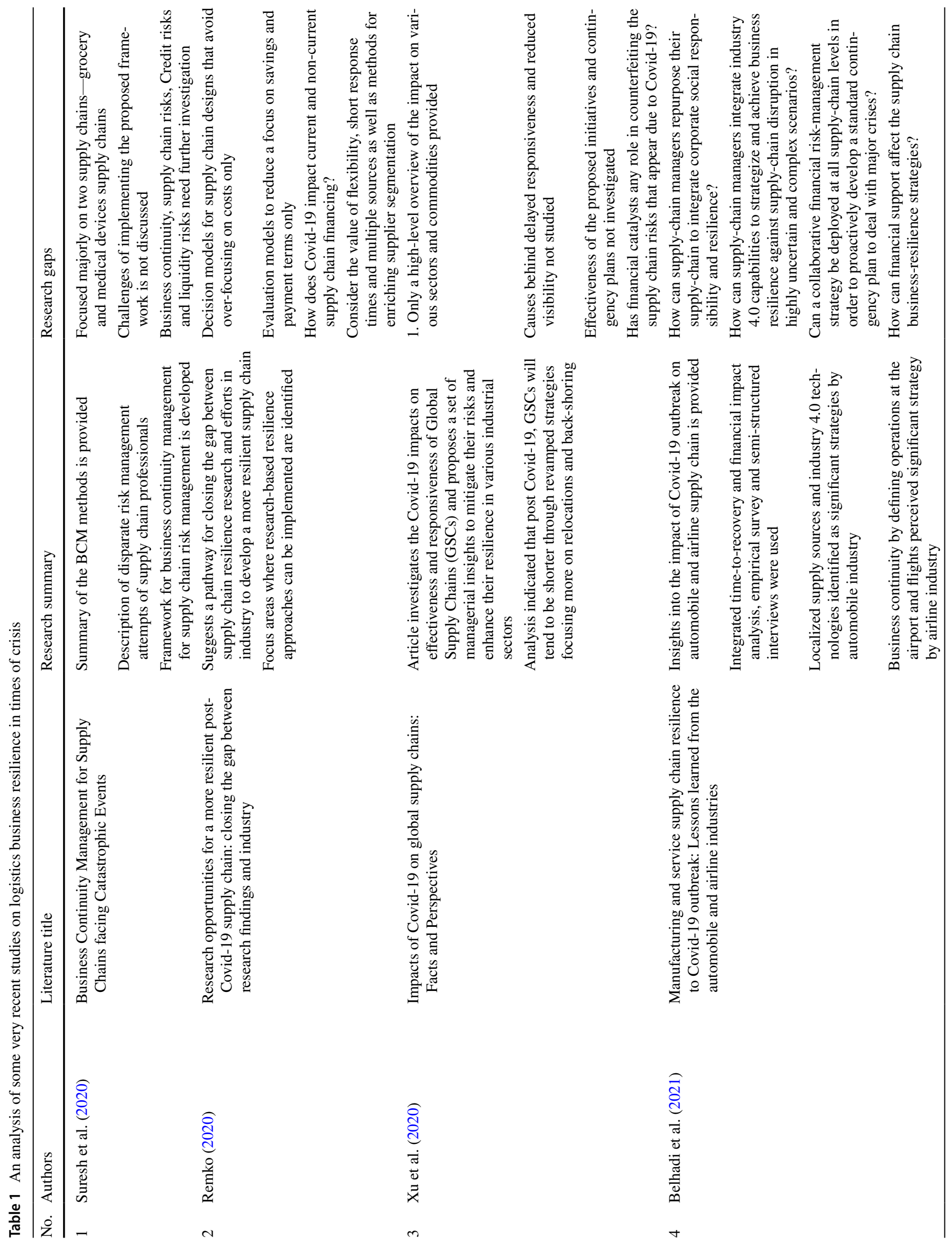

承 


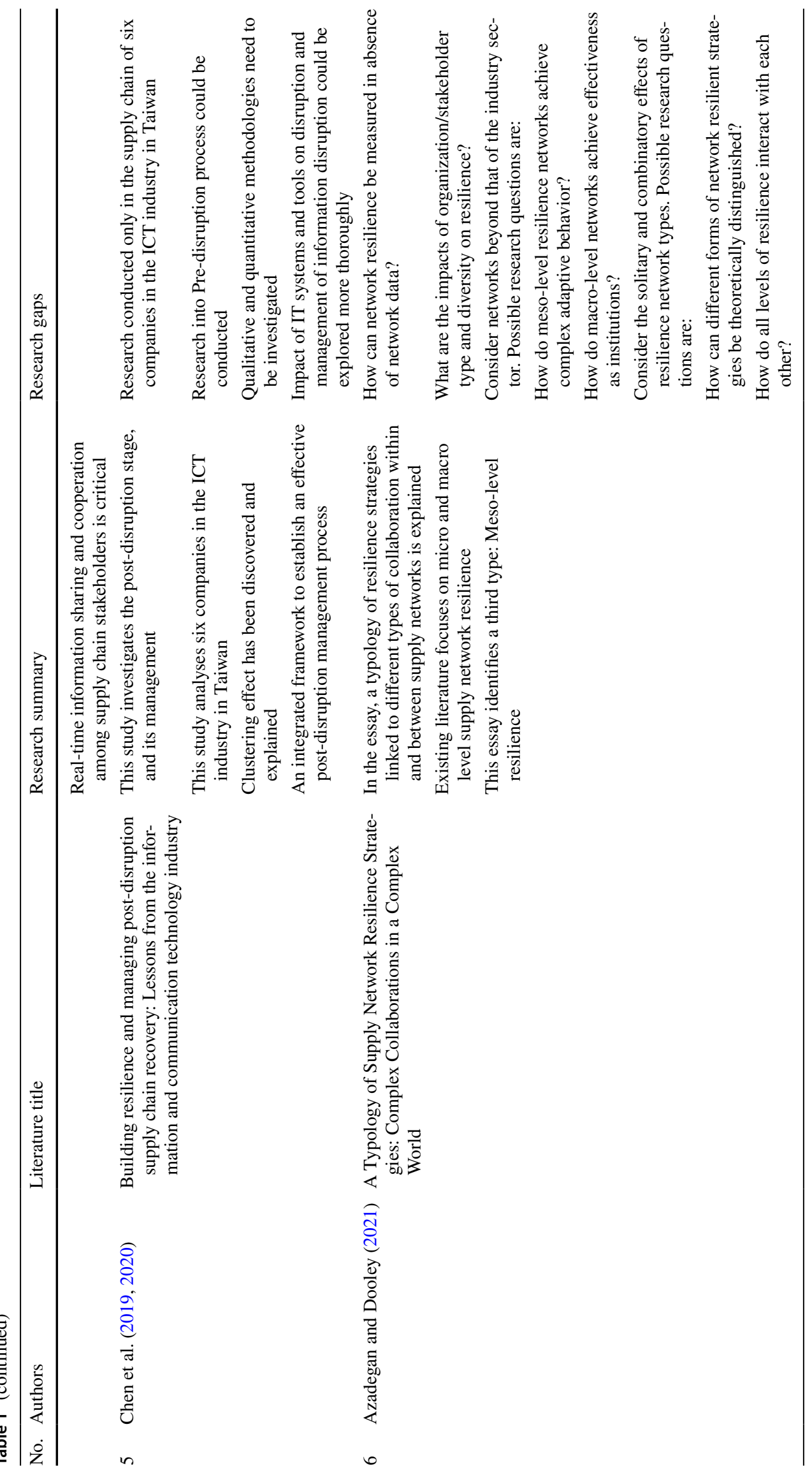


digital innovations and proper financial strategies to deal with emergencies cannot be overemphasized (Jing and Seidmann 2014).

\section{Financial resilience in the face of a major disaster}

Although the financial frameworks identified in the related literature were limited to small-scale networks, the influence of financial frameworks on business resilience and the trade-offs between firm robustness and the recovery time were some of the findings in the extant literature (Teece et al. 2017; Li et al. 2020). Cam and Ramiah (2014) studied the influence of systematic risk factors and econometric adjustments during catastrophic events, and established a positive ripple-effect relationship between financial resilience and economic stability. However, studies that focus on the influence of ripple effect in the context of supply-chain business performance are quite limited in number (Sharma and Naude 2021; Ivanov and Dolgui 2021). Some other studies also indicate that a supply-chain design level that incorporates the dynamic role of financial sustainability leads to a more effective business resilience (Fahimnia and Jabbarzadeh 2016). More recently, Gerth et al. (2021) assessed the effectiveness of financial product innovations in the UAE during the Covid-19 pandemic and found that availability and innovative usage of financial resources during the crisis was pivotal to the survival and recovery of various firms in the country that were financially distressed as a result of the Covid-19 pandemic.

Despite the foregoing, it is worthy of note that the impact of financial sustainability has still not been fully investigated in the logistics and supply chain domain. As a result, there is a lot of room for further investigation into the impacts of financial sustainability on supply chain survival in times of national or global catastrophes. Other emerging themes, such as the relationships between solvency capital requirement (SCR), resource-based view (RBV) framework, financial risk management, firm agility, and firm performance, have also been discussed in some existing studies, while the resource-based view (RBV) framework particularly has been shown to have positive effects on business reliance (Monaghan et al. 2017; Liu et al. 2018).

However, further studies with deeper conceptual and analytical investigations are still necessary in order to establish the universal applicability of these evolving trends (Albishri et al. 2020; Sundarakani et al. 2021), especially in the context of incorporating parallel memetic algorithms for managing disruptions and coping with uncertainties (Hasani and Khisrojerdi 2016). Some of the studies in the area have used the Grey Prediction Model (GPM) in a simulation to identify trends and forecast values of financial performance indicators along with error estimations (Rajesh 2017), but the model lacks extendibility in terms of incorporating other sustainability measures and indicators (Zhen et al. 2020).

A common limitation in many of the studies reviewed is that they were based on resilience simulations and modeling in company-specific contexts. Implementation of findings from such studies is also likely to be company-specific. Principally, many of the studies lack the comprehensive exploration of the concepts and variables that would robustly determine financial resilience in the context of supply chain networks across various industries. As a result, there is a strong need to investigate the financial-resilience frameworks that can trigger industry-wide recovery in times of national or global crisis (Teece and Linden 2017; Srivastava and Vishnani 2021). Without such robust financial frameworks, the industry-wide recovery time from a major crisis, such as the Covid-19 pandemic, would be very long, leading to potential business losses if the disruptive crisis continues. This study has addressed this research gap by adapting and extending the "financial resilience framework" of Barbera et al. (2017) into a business resilience model, which we have tested in the context of tackling the impacts of the Covid-19 pandemic in the UAE logistics and supply-chain industry (see Fig. 2).

\section{Modern emergency management: the 4-phase approach}

The 4-phase approach is widely used in various countries for the management of emergencies and disasters. This approach is essential in identifying the steps that must be taken by emergency management agency leaders to guarantee the safety of the society. The 4-phase approach acts as a guideline for the international principles of emergency management standards. The approach comprises the following activities (as depicted in Fig. 1):

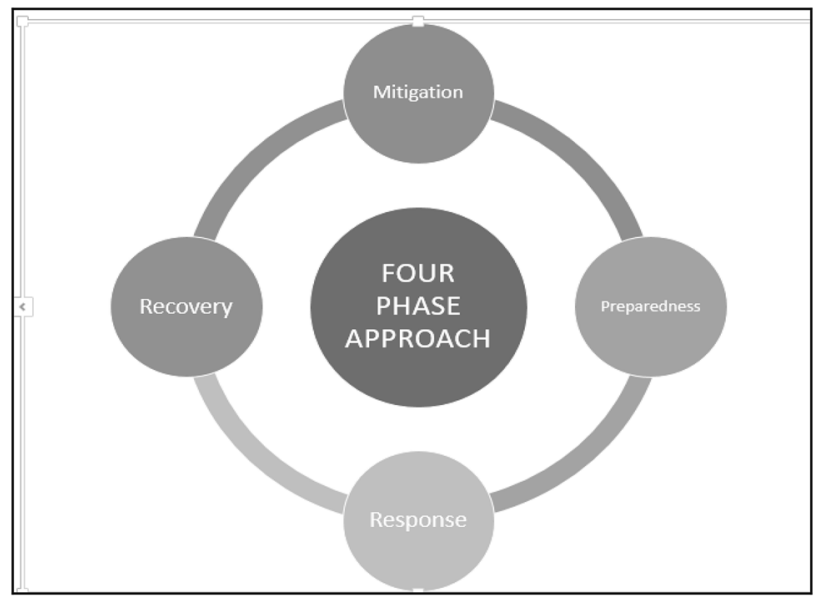

Fig. 1 The 4-phase approach emergency management. (Source Compiled by the authors from the extant literature reviewed) 
Mitigation: The first phase involves eradicating either or both the probability and/or the consequences of a particular hazard. The primary objective of this phase is to analyze, in both structural and non-structural ways, the critical issue at hand, and ensure it does not have a significant negative effect on the society, (Parsons 2008).

Preparedness: This is a result-driven phase, which increases the chance of survival of the individuals within a community whose lives have been disrupted because of the disaster. It also aims to minimize the financial loss facing the people, by appropriately equipping them with means of coping with the emergency (Alexander 2005). Due to the critical role of this phase in the community, ample research resources and time need to be devoted to studies on this phase in order to ensure that emergency organizations retain the best technical and procedural knowledge and skills for accomplishing the goals of the stage (Dillon et al. 2009). Rapid emergency response is of utmost importance, and is usually considered a failure if the actions carried out during this preparedness phase is inadequate or ineffective (Waugh and Tierney 2007).

Response: The response phase includes taking all necessary actions and precautions to ensure the possible arrest of the emergency situation in very little time, to minimize its negative impact, and to avoid any additional suffering and loss of life and property. One very important component of the response phase is "relief," which is widely used within international emergency management circles; and the estimated degree of danger and risk involved in the emergency determines the level of skills and expertise required to handle it occurrence (Brito 2007).

Recovery: The last phase focuses on normalizing the lives of the individuals and groups affected by the disaster. This step can only be taken after the response phase has been completed, and can take months or even years to conclude (Coppola 2015).

The above four phases provide guidelines for specifying the duties of all emergency responders. They also help the administrators to analyze the situation and prepare appropriate levels of response to minimize the casualty and effectively manage the situation. The framework helps to ensure that all the plans and actions are implemented among all agencies collaboratively, for effective risk reduction and maximum safety for the stakeholders.

\section{Research model development-the business resilience framework}

\section{Synthesizing our business resilience constructs into a research model}

In developing a conceptual model that would characterize our major construct of interest-business resilience in the face of Covid-19 - we adopted the "engineering perspective on resilience" in line with Barbera et al. (2017). This perspective emphasizes the employment of an organization's "capacities" to repel and diminish (or eliminate) the negative impacts (shocks) of a crisis on its business operations. At the onset of the crisis, the organization promptly mobilizes certain "capacities," especially additional financial resources, in order to cope with, recover from, and/or adapt to the new critical environment. By so doing, the organization assumes a robust and resilient attitude that enables it to swiftly recover from the negative impacts of the crisis and ensure its long-term survival and operational continuity in the face of the crisis.

Using the following seven (7) variables culled from our literature review, we synthesized both the "anticipatory (intervention) and coping capacities" in our research model in line with Barbera et al. (2017). We argue that employing these "capacities" would enhance the business resilience of supply chain and logistics operators in the UAE by helping them to mitigate the disruptive shocks of the Covid-19 pandemic on their business operations. In addition, conceptualizing the model has also enabled us to measure the operators' resilience outcome in the context of how robustly they have continued to deliver efficient services, maintain customer satisfaction, and increase, decrease or sustain their customer retention levels despite the unrelenting pandemic. The seven variables that constitute the main constructs of our conceptual research model include:

1. Government support

2. Financial resource (Funding)

3. Technology application

4. Innovative value addition (new processes)

5. Service delivery efficiency

6. Customer satisfaction

7. Customer retention

With the above variables, we synthesized the research model as a novel dimension that extends the "financial resilience framework" developed by Barbera et al. (2017) 
Fig. 2 The conceptual model of the research-business resilience in the face of Covid-19 pandemic (model construction based on the "financial resilience framework" of Barbera et al. (2017)

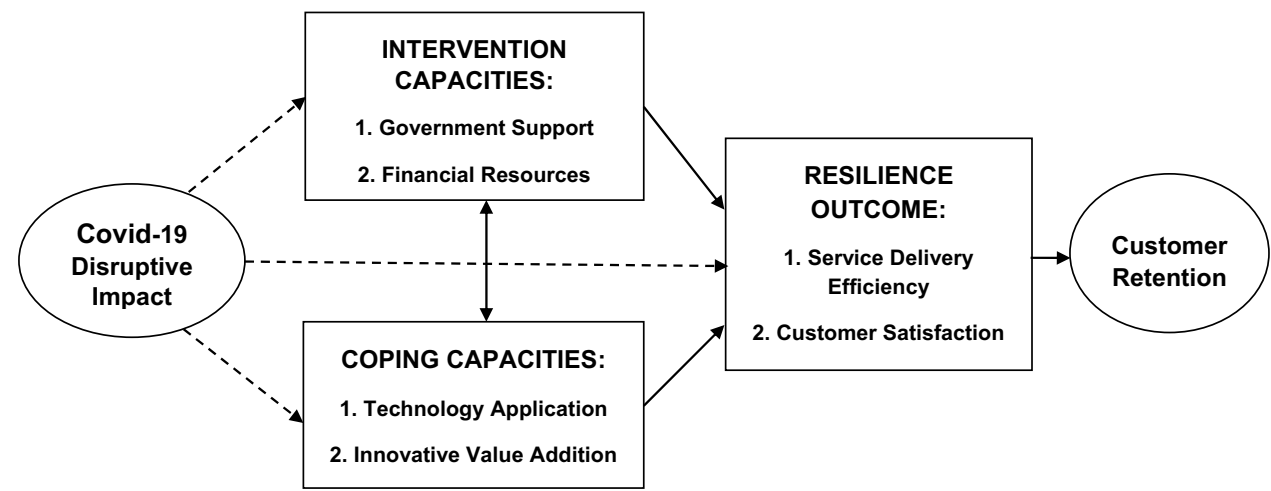

in the context of the UAE supply chain and logistics industry's business resilience in the face of the ongoing Covid-19 global pandemic (see Fig. 2).

\section{Research methodology and data collection}

\section{Sampling method}

This qualitative study is focused on examining the financial and business resilience of the supply chain industry in the UAE as empowered by the financial support of the UAE Government in the face of the global Covid-19 pandemic. The strategic measures taken by some of the industry operators to mitigate the risks and disruptions of the pandemic, with the financial assistance of the Government, were investigated to determine their resilient effectiveness. Due to the nation-wide lockdown in the country almost throughout the first year of the pandemic, our data collection had to be done online as videoconference in-depth interviews of top executives of the five (5) largest supply chain/logistics companies in the country using the Zoom videoconference platform. For ethical purposes, the identities of both our sample subjects and their organizations have been kept anonymous, but the business focus of their organizations has been identified (see Table 3). Qualitative studies enable the collection of in-depth data directly from individuals (one by one, face to face), the analysis of which afford the researcher the ability to gain deeper longitudinal insights into the issue being investigated and into each respondent's attitudinal dispositions concerning the issue (Mohajan 2018).

Our in-depth interviewees were selected because they are experts in the field of supply chain and logistics management. They are top-level decision-makers within their respective organizations, and have therefore been involved in handling their companies' business activities for many years. Due to their vast industrial knowledge and experience, they have also been representing their organizations in the industry's collaborations with the UAE Government regarding the country's "fast and furious response" to the disruptive effects of the Covid-19 pandemic. In addition, they are also involved in the industry's self-directed collaborative efforts to achieve a rapid recovery of that sector of the economy. The identified experts were contacted to participate in our in-depth interviews, and they gave their consent before the interviews were conducted in the months between December 2020 and February 2021. The in-depth interview method of qualitative data collection has been shown to be a sound approach for mining data that would enable thorough exploration of all longitudinal dimensions of any problem or task in any field of study under complex situations (Yin 2003). Our qualitative data have been analyzed with appropriate rigor in line with the suggestions of Locke (2002), Locke et al. (2020), and Shah and Corley (2006).

\section{Operationalizing the research constructs}

To operationalize the central construct in our researchbusiness resilience in the face of Covid-19 - the gaps we discovered in our literature review were pulled together as our study variables. The variables were then used to configure the conceptual model of our research as an extension of the "financial resilience framework" developed by Barbera et al. (2017). The model afforded us the ability to examine the business and financial resilience of the UAE logistics and supply-chain service providers in the face of the disruptions caused by the ongoing Covid-19 pandemic during its first year (2020). Below is a summary of the conceptual meanings of the seven variables, which also constitute the analytical nodes in our qualitative data analysis using the NVivo 12 software:

1. Efficient service delivery-The ability to provide complete and uninterrupted customer-service deliveries despite the destructive impacts of the crisis. 
2. Innovative value addition-Innovative processes and strategies introduced in the service operations to retain or increase patronage despite the crisis.

3. Technology application-Novel technologies introduced in the service-delivery operations to overcome the negative impacts of the crisis.

4. Government support-Non-monetary, organizational and motivational interventions and operative guidelines issued by the government as part of the collaborative management of the situation to mitigate the disruption of economic activities during the crisis.

5. Financial resource (funding) — Continued availability and effective utilization of additional financial resource provided as a bailout by the government or any other organization for combating the destructive effects of the crisis.

6. Customer satisfaction-The rate and level of satisfaction attained among new existing and existing customers due to continued service efficiency despite the crisis.

7. Customer retention-The number of current customers retained or lost, and new customers gained or failed to gain, due to the level of customer satisfaction attained during the crisis.

To collect and analyze our data in order to determine the business and financial resilience of supply chain and logistics operators in the UAE, we designed the in-depth interview questions to cover all the seven (7) variables in our conceptual model as explained above. An extra question (the first question) to confirm if the respondents' companies actually felt any impact of the crisis was also added, making eight (8) interview questions in total (see Table 4). The variables have enabled us assess the overall service delivery efficiency of the operators in the face of any business interruptions caused by Covid-19 during its first full year (Shen et al. 2020; Atayah et al. 2021). In Table 2, we present the in-depth interview questions addressing the variables that define our central construct of interest as used during our data collection. Also provided in Table 2 are the rationales further explaining each question and the contributory role it plays as a variable in helping to determine the business and financial resilience of the supply chain and logistics operators in the country.

\section{Data collection by in-depth interviews of experts}

Data collection in qualitative research involves obtaining non-numerical data, mostly consisting of discussions, opinions and explanations of the phenomena of interest by the respondents, who are usually very knowledgeable about the issues involved or the object of the investigation. It involves the interviewer asking the respondents pertinent questions that allow them to share their expert-knowledge, perspectives, opinions and experiences about the subject matter of the investigation. The data collection technique is usually a semi-structured method that requires the willful consent of the sampled respondents to be involved in the open-ended interviews (Gopaldas 2016).

In this research, the data collection technique used is in-depth interview, which is a qualitative method that may include data mining instruments such as observations, focus group discussions, or one-to-one interviews. In in-depth interviews, the interviewees answer the interviewer's questions either face-to-face or via a remote medium such as a telephone, email, or a videoconference platform (Bonevski et al. 2014). Through this personal interaction, it is easier to gain a thorough subjective understanding of the phenomenon of interest - in this case, the business resilience of supply chain and logistics operators in the UAE. In this study, we have employed online one-to-one in-depth interviews, conducted via the Zoom Videoconference platform between December 2020 and February 2021.

As earlier stated, five very senior-executive experts from the top five (5) logistics and supply-chain service providers in the country were interviewed for the study (Table 3 ). The choice of these top executives was based on their expertise, their years of experience in the logistics and supply chain industry, and the large sizes of their companies as the top five in the country. In addition, the business operations of their companies cover various types of logistics servicesincluding bulk distribution, haulage, cargo handling, local and international freighting, shipping, clearing and forwarding, and logistics solutions.

\section{Data presentation, analysis, and discussion of findings}

\section{Data presentation}

In Table 4, we present the transcribed verbatim responses to our eight (8) questions as provided by the top UAE supplychain and logistics experts during the in-depth interviews variously held between the months of December 2020 and February 2021.

\section{Confirming data reliability and objectivity using the CTDC framework}

In order to ensure reliability and objectivity of qualitative research data, various methodology scholars have advised that qualitative data should be collected in such a way that another researcher can replicate the same study elsewhere with respondents of similar characteristics under the same conditions and obtain similar results (Yin 2003; Shah and Corley 2006). It has also been suggested that collecting 


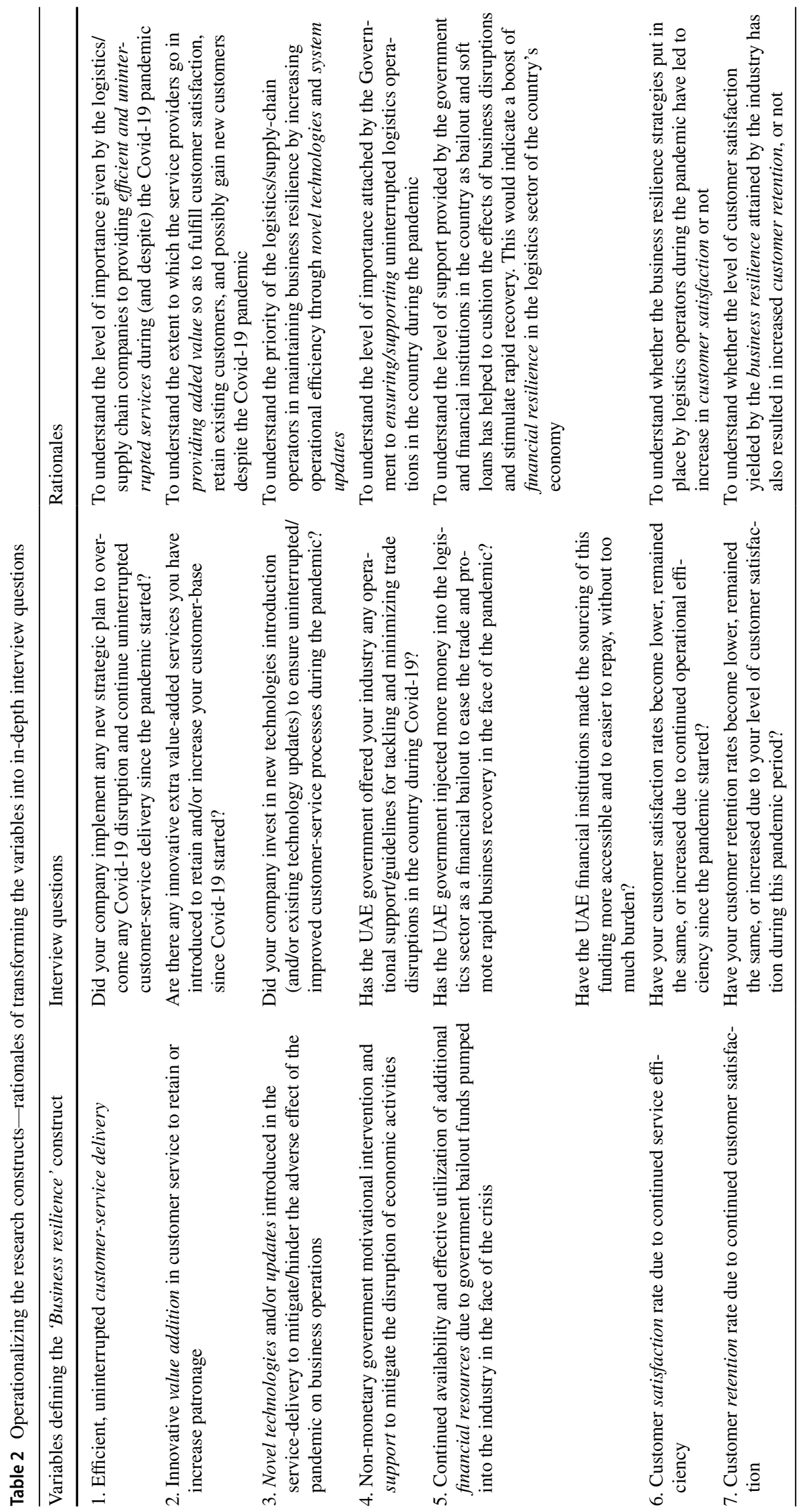

就 
Table 3 Interview sample subjects - top 5 supply chain/logistics experts in the UAE

\begin{tabular}{lllll}
\hline Company & Nature of company business & Respondent's position & $\begin{array}{c}\text { Years of industry } \\
\text { experience }\end{array}$ & $\begin{array}{c}\text { Contact } \\
\text { with cus- } \\
\text { tomers }\end{array}$ \\
\hline Company A & Air freight & Executive director, export services & 18 years & Yes \\
Company B & Break bulk cargo & Customer care group head & 12 years & Yes \\
Company C & E-Logistics & Founder \& CEO & 15 year & $10+$ years \\
Company D & Tech-road transporter & Snr. customer services manager & 13 years & Yes \\
Company E & International freight forwarder & Head of pricing and sales & & Yes
\end{tabular}

qualitative data in a "formal and systematic manner," with the same interview questions asked similarly across all the respondents, will equally enhance the "trustworthiness" and "generalizability" of findings from the qualitative data (Locke et al. 2002; Locke et al. 2020).

To achieve this, the above scholars suggest that qualitative researchers should use data-collection methods such as in-depth interviews and/or direct observations of the "people directly experiencing the phenomenon" of interest (Shah and Corley 2006:1928; Locke et al. 2002). It is therefore understood that collecting qualitative data in the above ways would confirm the "Credibility, Transferability, Dependability and Confirmability (CTDC)" of the data (Shah and Corley 2006:1830, citing Lincoln and Guba 1985).

In this study, we have conducted in-depth interviews with experts who are directly operating in the logistics and supply chain industry at very senior management levels. Their companies are also directly grappling with the impacts of the Covid-19 pandemic. They have numerous years of first-hand knowledge and experience of management in the industry, and are also directly involved in managing the Covid-19 disruptions within their organizations. Moreover, the same set of in-depth interview questions was used for all the expertrespondents in a formal data-collection manner, all in line with the above suggestions of Locke et al. (2002) and Shah and Corley (2006).

In terms of analysis of qualitative data, content analysis and keyword frequency of the constructs of interest are some of the qualitative analysis methods suggested in the extant literature (Denzin et al. 2006; Locke 2002; Locke et al. 2020; and Yin 2003). These two analytical methods establish and confirm the reliability of the associations between and across the data received from all the qualitative research respondents (ibid). In line with the CTDC framework for ensuring "trustworthiness" of qualitative research data (Shah and Corley 2006:1830 — citing Lincoln and Guba 1985), we ensured that our interview respondents also possess the required "extended engagement in the field" (ibid:1830) as they are all experts in the area of this study, which meets the "Credibility" dimension $(\mathrm{C})$ of the framework. We have also presented in this paper a detailed description of the "concepts, categories, and structures related to the processes revealed in the data" (ibid), and our data therefore comply with the "Transferability" dimension (T) of the framework. In addition, we employed the "purposive and theoretical sampling" (ibid) method suggested by the authors, in the sense that we were judgmental and selective in deciding to sample only experts in the logistics and supply chain industry who have had more than 10 years of experience in this same industry.

Moreover, as also suggested by the methodology scholars, we ensured that our 'informants' confidentiality (was) protected," thereby complying with the "Dependability" dimension (D) of the framework (ibid). Lastly, we were meticulous in recording and managing the data we collected from the respondents, and have presented a "verbatim transcription of the interview" (ibid) in this paper (Table 4) as required by the fourth/last dimension of the "Trustworthiness" (CTDC) framework, which is the "Confirmability" dimension (C). Based on the foregoing, we are confident that we have complied with all requirements for ensuring the reliability and objectivity of our qualitative research data as contained in the existing literature.

\section{Data analysis and discussion of findings}

\section{Analysis of the verbatim responses}

Answering our first interview question, two of our five respondents (40\%) agreed that Covid-19 had affected their businesses by slowing down their operations during the pandemic lockdown. The other three $(60 \%)$ asserted that it did not do much but they were forced to downsize their manpower due to the lockdown and the Government's safety protocols during the first few months of the global pandemic. However, we consider even the downsizing of the number of their employees during the pandemic as an impact of the Covid-19 pandemic.

For the second question, all five experts (100\%) confirmed that their companies implemented various strategies in order to keep up their efficient and uninterrupted operations, such 


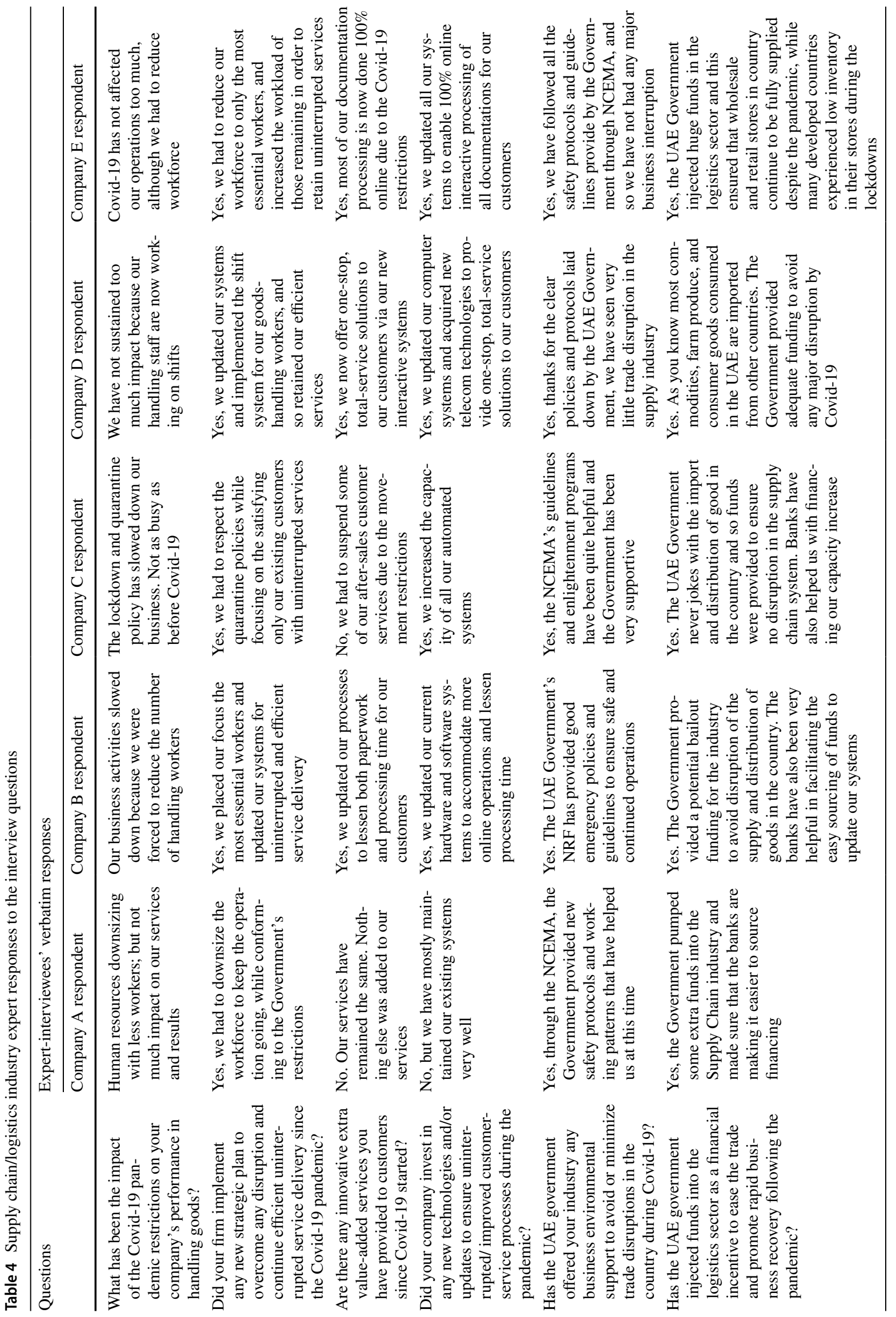

我 


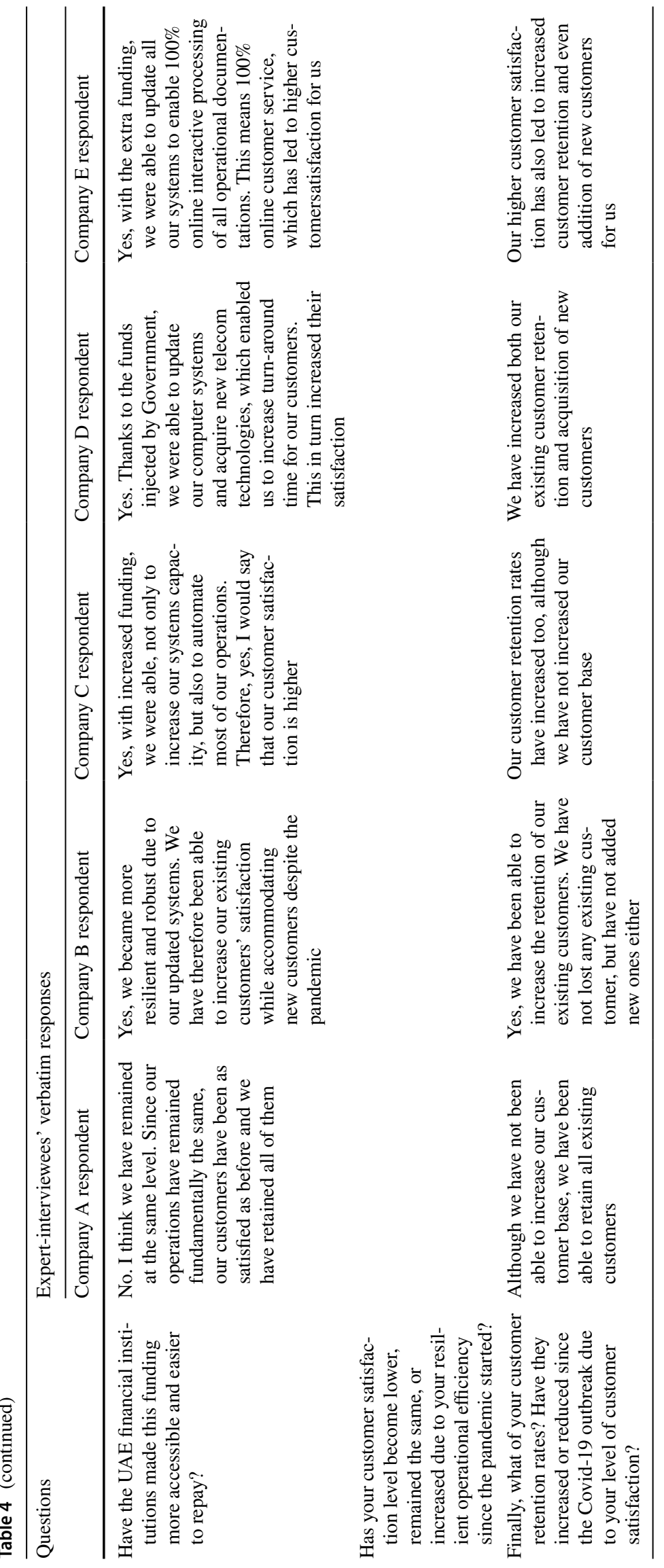


as focusing on the most important parts of their business operations, updating their IT systems, downsizing the operational staff, and boosting online customer services. These measures ensured that their companies remained fully operational and profitable despite the pandemic.

Responding to the third question, three of the respondents (60\%) confirmed that the companies became more innovative by offering added value to their customers, including lessening paperwork volume and processing time, introducing new interactive systems, and now doing all document processing exclusively online. The other two companies (40\%) did not add any new strategies apart from downsizing employees to cut cost and remain profitable.

For the fourth question, four of the five experts $(80 \%)$ confirmed that their companies implemented new ICT technology applications with new and upgraded systems to shorten their processing time, automate their entire process, and make their operations more accessible and interactive for the customers. Only one of them (20\%) confirmed that his company maintained their systems at the same existing technological level as before the pandemic.

Regarding the fifth question, all five industry-experts (100\%) confirmed that the UAE Government gave the logistics and supply chain industry in the country adequate operational support and safety guidelines during the pandemic. Through the emergency guidelines of the NRF and the safety protocols of the NCEMA (2019), the Government provided new policies that ensured continued optimal and safe operations by all companies during the pandemic period.

Answering the sixth question, all the experts (100\%) also confirmed that the UAE Government pumped extra funds (financial bailout) into the industry during the pandemic in order to enable banks and non-bank financial organizations provide additional financial resources to the logistics and supply chain companies in the country during the pandemic crisis. This sixth question could easily be classified as the most important factor in the study because it has to do with the very essential financial bailout of the industry by the UAE Government, and is pivotal to making all the other resources and strategies possible and effective (Atayah et al. 2021). All five experts (100\%) confirmed that the government pumped in adequate extra funding into the industry in order to ensure that no logistics/supply chain company lacked any form of financial assistance during the pandemic period. This financial assistance enabled the entire industry to remain financially resilient in providing efficient, uninterrupted business services throughout the period of the pandemic (Huang et al. 2020; Atayah et al. 2021).

Based on the expert responses to the fourth, fifth and sixth questions above, it is obvious that the timely and extensive support provided by the UAE Government contributed immensely to the uninterrupted operations of all the companies in the logistics and supply chain industry. The result was felt all over the country, to the effect that throughout the lockdown period, no retail store and no business in the country lacked any of their goods to sell. The entire population of the country was able to buy anything they wanted during the lockdown and afterward. There has not been a single day of "out-of-stock" notice for any product in any store anywhere in the country since the pandemic started. This has boosted consumer confidence in the country to a new high level of 118 points (tradingeconomics.com 2021).

In response to the seventh question, four of the five experts (80\%) confirmed that the satisfaction level of their customers increased during and after the pandemic period due to the innovative and resilient strategies they implemented during the pandemic period to ensure efficient uninterrupted services. Only one of the experts (20\%) responded that his company maintained the same level of customer satisfaction as before the Covid period, in such a way that although their customer satisfaction level did not increase, it also did not decrease.

In the same vein, for the last (eighth) question, the same four of the five respondent-experts (80\%) affirmed that their companies were also able to increase their customer retention rates due to their operational resilience, service continuity, and increased efficiency during the pandemic period. The same one expert (20\%) also stated that his company maintained the same level of customer retention as before the Covid-19 breakout.

\section{NVivo "text search query" (word count) analysis}

To analyze our qualitative data in this study, we applied two types of "query" analysis in the NVivo 12 analytical software to establish the trends of occurrence and relationships between the vital keywords across the expert opinions of all our study respondents. These two approaches are the Text Search Query and Keyword Association analyses in NVivo 12. They help to establish both the keyword count (frequency) and the keyword relationships across all the respondents' expert-opinions about all the variables in the study (see Table 5 and Figs. 3 and 4).

After inputting the five industry experts' verbatim responses into the NVivo 12 software, we ran the Text Search Query with the instruction for the software to identify the top 25 most-recurrent keywords across the five experts' verbatim responses. Table 5 shows the 25 most-recurrent keywords identified across the dataset, as well as their total frequencies and percentages. In addition, Fig. 3 shows a pictorial representation (keyword mapping) of the same top 25 most-recurrent keywords in their comparative graphic sizes, relative to their counts (frequencies).

From the above table and figure, one can see that the top seven (7) most-recurrent keywords our NVivo 12 text search query are Customer, Government, Systems, Retention, 
Table 5 Keyword frequency-using the "text search query" (wordcount) analysis in NVivo 12 (results show the 25 most-recurrent keywords across the respondents' verbatim opinions). Source Data analysis with NVivo 12

\begin{tabular}{|c|c|c|c|}
\hline Word & Length & Count & Percentage \\
\hline Added value & 5 & 7 & 3.535353535 \\
\hline Application & 11 & 5 & 2.525252525 \\
\hline Availability & 12 & 5 & 2.525252525 \\
\hline Company & 7 & 5 & 2.525252525 \\
\hline Covid-19 & 5 & 8 & 4.04040404 \\
\hline Customer & 8 & 21 & 10.60606061 \\
\hline Customers & 9 & 12 & 6.060606061 \\
\hline Delivery & 8 & 6 & 3.03030303 \\
\hline Existing & 8 & 7 & 3.535353535 \\
\hline Finance & 7 & 5 & 2.525252525 \\
\hline Funds & 5 & 5 & 2.525252525 \\
\hline Government & 10 & 17 & 8.585858586 \\
\hline Impact & 6 & 7 & 3.535353535 \\
\hline Increase & 8 & 6 & 3.03030303 \\
\hline Increased & 9 & 9 & 4.545454545 \\
\hline Interview & 9 & 5 & 2.525252525 \\
\hline Online & 6 & 5 & 2.525252525 \\
\hline Operations & 10 & 5 & 2.525252525 \\
\hline Processing & 10 & 5 & 2.525252525 \\
\hline Retention & 9 & 10 & 5.050505051 \\
\hline Satisfaction & 12 & 7 & 3.535353535 \\
\hline Service & 7 & 9 & 4.545454545 \\
\hline Services & 8 & 7 & 3.535353535 \\
\hline Systems & 7 & 13 & 6.565656566 \\
\hline \multirow[t]{2}{*}{ Updated } & 7 & 7 & 3.535353535 \\
\hline & & 198 & 100 \\
\hline
\end{tabular}

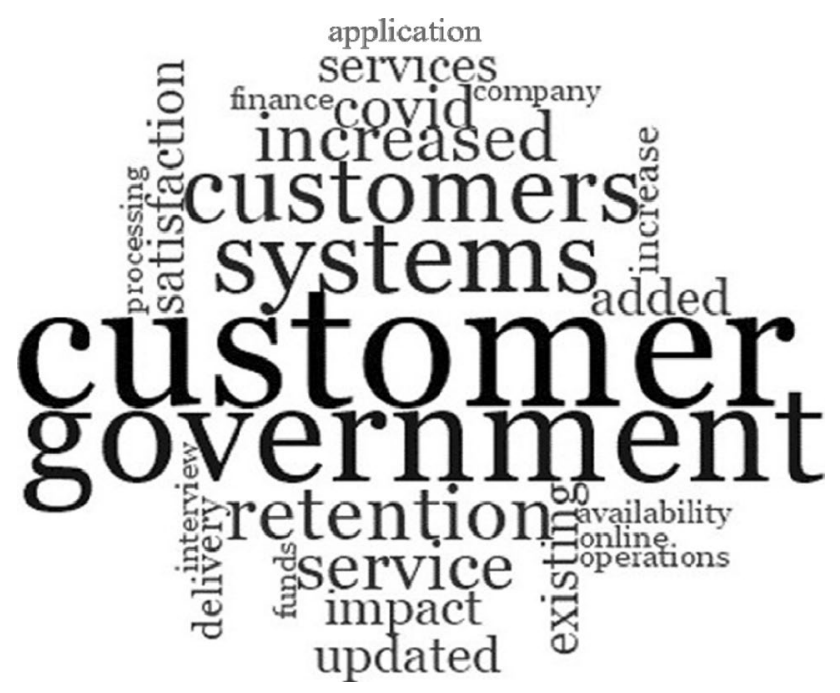

Fig. 3 "Keyword mapping" analysis in NVivo 12: representing the 25 most recurrent keywords across the expert opinions in comparative graphic sizes
Service, Covid increase, and Satisfaction. These keywords aptly summarize the core trend in the study, and help to establish the business resilience of the UAE logistics and supply chain companies in the face of the Covid-19 pandemic during the months covered in the study. The impacts of Government support, and the companies' updated IT Systems, helped the industry operators to improve Customer Service, increase Customer Satisfaction, and thereby increase Customer Retention despite the disruptive effects of the pandemic.

\section{NVivo keyword association analysis}

We also ran a keyword association analysis in the NVivo 12 software to establish the relationships between Satisfaction, Retention, and the Customer. The result, as presented in Fig. 4, shows direct relationships among the three keywords. Satisfaction is directly related to Retention, and both of them are also directly related to the Customer. We can therefore safely conclude, in agreement with the experts interviewed, that the increase in their companies' customer satisfaction is what has led to increase in their customer retention even in the face of the Covid-19 pandemic (Harrison et al. 2014; Abu-Salim et al. 2017).

Lastly, observing all the above keywords (Table 5 and Figs. 3 and 4) extracted by the two NVivo 12 analyses of our dataset, one can clearly see that the variables that define our overarching research construct (resilience) are mostly the same ones also extracted by the qualitativedata analysis software across the responses of all the five experts. This is a confirmation that these keywords (variables) have truly contributed to establishing and confirming the business resilience accomplished by the logistics and supply chain companies in the UAE during the Covid-19 pandemic (Soni et al. 2014).

\section{Conclusion}

\section{Theoretical implications}

At times of national or global crisis (such as the Covid-19 pandemic period), financial resources suddenly become scarce in many organizations. It is therefore imperative for major industries to seek government financial bailout, and to use the bailout funds judiciously in revamping their operational models and IT systems as suggested by Teece and Linden (2017) and Teece (2018). This will ensure that they increase both their production and service-delivery efficiencies as an industry, and also collectively remain relevant as a major sector of the country's economy. In addition, such an operational overhaul will equally help 


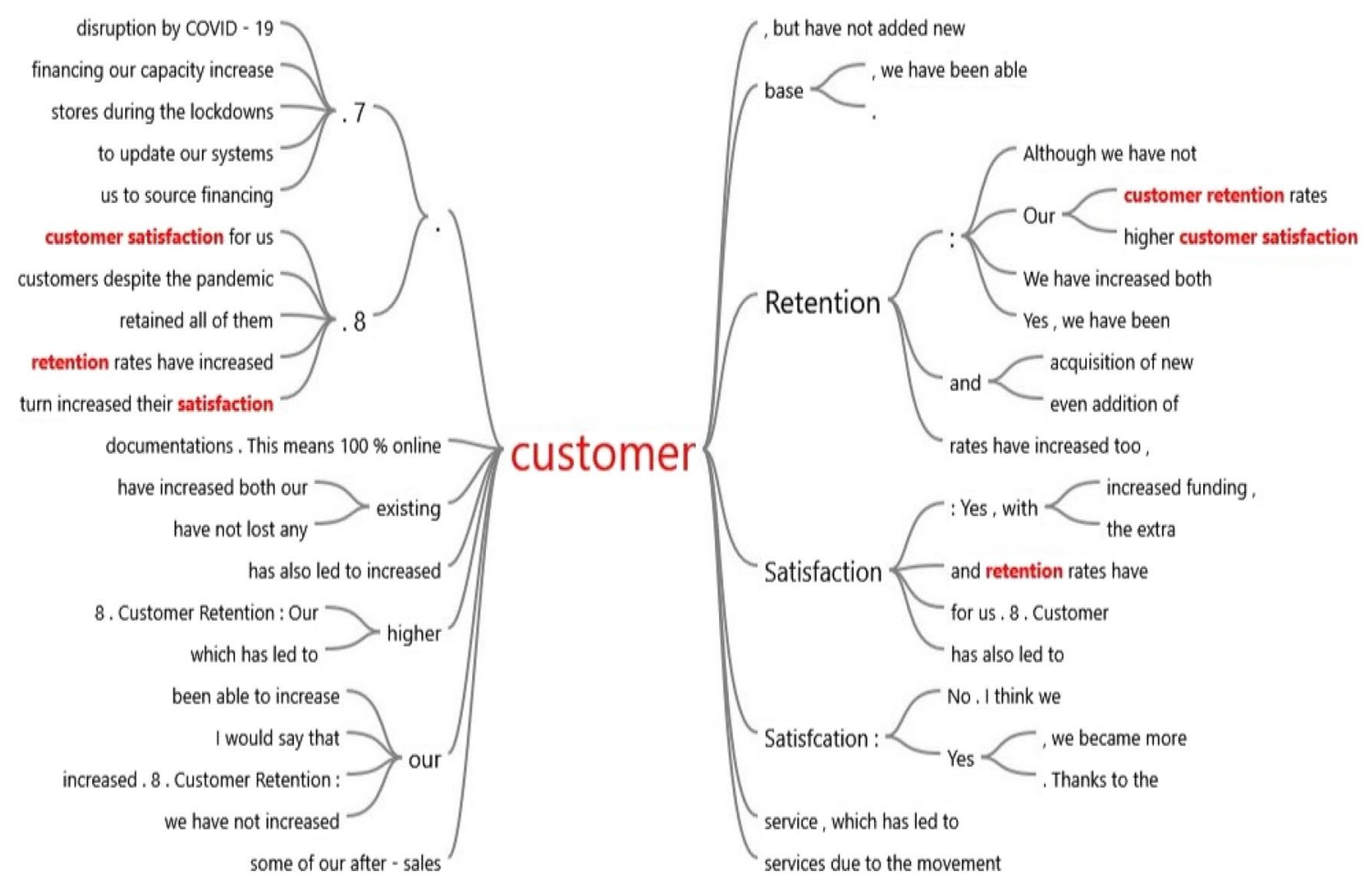

Fig. 4 "Keyword association" analysis in NVivo 12: association of "satisfaction" and "retention" to the "customer" in the experts' opinions

certain member-organizations to attain/retain competitive advantage within their industry (Abu-Salim et al. 2020).

Our present study has revealed that the above assertion is not only true but also feasible. Thanks to the UAE Government's financial bailout, the logistics and supply chain industry in the country was able to revamp its digital capabilities and operational strategies in a dynamic way that has demonstrated their business resilience in the face of the Covid-19 crisis (Atayah et al. 2021). Consequently, this study has contributed to verifying the Dynamic Capability Theory (DCT) proposed by Teece et al. (1997). The implication is that, in this twenty-first century, digital transformation of operational processes has become the most vital necessity consequent upon the injection of additional financial resources into any industry during a national or international crisis. As a result, the DCT framework has become even more relevant today for attaining business resilience in any major industry in times of major national or global emergencies (Kuuluvainen 2012).

\section{Managerial implications}

As evidenced in our study, the business resilience accomplished by the UAE logistics and supply chain industry has led organizations within the industry to attain several operational efficiencies and business benefits. These include faster production/delivery timing, shorter waiting time for customers, increased speed to the market, higher scope of operations, and higher levels of new customer acquisition, customer satisfaction, and customer retention (Onyia and Tagg 2011; Abu-Salim et al. 2017). Our study therefore indicates that emerging markets, such as the UAE, possess greater market opportunities and substantial business benefits in embracing disruptive innovations during major crises, especially if such innovations are enabled by a timely government financial support.

Existing literature seems to suggest that only the developed countries are technologically advanced enough to implement new data analytics and the latest digitization initiatives (Sundarakani et al. 2019), but this study has shown that a fast-developing country like the UAE can also successfully implement such initiatives. We therefore recommend that the logistics and supply chain industries of other fast-developing countries that are still straining under the Covid-19 pandemic should also adopt the business and financial resilience strategies discussed in this paper in order to sustain and improve their logistics operations. As we see a wave of digital transformations in the vertical logistics industry (Kamran et al. 2021), robust and resilient decisionmaking approaches and solutions have become more pertinent for logistics companies to maintain or surpass their pre-Covid output levels. 


\section{General synopsis of the study}

To conclude this study, the verbatim (expert-opinion) data and analyses presented in this paper affirm the business and financial resilience accomplished by the logistics and supply chain industry in the UAE in the face of the Covid-19 global pandemic. We have also demonstrated that the variables we examined were indeed able to define the ability of the industry to mitigate the disruptive impacts of the pandemic on their business operations in line with Li et al. (2020).

The UAE Government, through the NCEMA and NRF, provided robust operational and financial support to the logistics and supply chain industry in the country, which has helped them to employ and implement innovative strategies in tackling the disruptive business condition occasioned by the Covid19 pandemic. To effectively mitigate the consequences of the pandemic, NCEMA ensured a good leadership framework and effective safety coordination among all the sub-agencies for effective management of the Covid-19 crisis in the country. Together with the robust financial bailout by the Government, this helped the logistics and supply chain companies to introduce new ICT systems and novel strategies that have enabled then to attain greater business resilience in the face of the crisis. This has translated into the countrywide industry being able to retain steady and uninterrupted distribution of goods and services throughout the period of the pandemic, much better than many developed and developing countries have done (Atayah et al. 2021).

Lastly, our findings reveal that the disruptive impact of Covid-19 in logistics and supply chain operations in the UAE has been quite minimal due to the UAE Government's operational and financial support to the industry. As a result, the logistics and supply chain companies were able to demonstrate optimal business resilience in their operations despite the global pandemic (Goldbeck 2020). It is therefore our avid assertion, in agreement with Shen et al. (2020), that financial support (especially from the government) is a highly indispensable factor in the preparedness of the logistics and supply chain industry toward effective response, mitigation, and recovery in the face of such a global disaster. Consequently, a financial bailout, such as the one implemented in the UAE is highly crucial for ensuring a steady supply and distribution of commodities in any country impacted by a major national or international crisis (Alexander 2005; Parsons 2008; and Coppola 2015) such as the Covid-19 pandemic.

\section{Limitations and further research}

\section{Limitations}

The major limitation in this research was the lockdown experienced in the entire country during first year of the
Covid-19 pandemic. As part of the safety precautions, the UAE Government imposed a no-movement curfew for 24 hours and that made it difficult to get in contact with other experts of the industry. As a result, we were only able to obtain consent from the five experts interviewed in this study. Fortunately, they happen to be industry-experts in the top five logistics companies operating in the country. Nonetheless, given our thorough analysis of their verbatim expert opinions in line with the CTDC framework for ensuring "trustworthiness" of qualitative research data (Shah and Corley, 2006:p.1830), we are confident that our findings can be applied in the logistics and supply-chain resilience context of any other country if similar critical conditions are maintained.

\section{Future research}

There is a lot of scope for further research to understand more economic and financial impacts of the Covid-19 pandemic on different industries in many countries. While this study has focused on the intervention strategies of the government and logistics/supply chain industry in mitigating the impacts of Covid-19 on business operations, further studies could focus not only on the logistics/supply chain companies but also on the impacts of the pandemic on their customers, or on other very different industries. For example, the impact of Covid-19 on the buying power of retail customers could be studied, regarding how they have coped with the pay slashes by various employers during the pandemic, and whether or not they are willing to pay higher prices to get better services in times of such a crisis. Lastly, future researchers could also examine and possibly compare/contrast the pandemic impacts and mitigation/recovery strategies in the logistics industries (or other industries) across various other countries.

Acknowledgements The authors would like to acknowledge the support provided by Subhansu Singhvi and Devavrata Dixit in collecting data about the industry and for providing additional support. The authors would like to appreciate the blind reviewers who have provided their valuable comments, which enhanced the quality of this paper.

\section{References}

Abu-Salim, T., O.P. Onyia, T. Harrison, and V. Lindsay. 2017. Effects of Perceived Cost, Service Quality, and Customer Satisfaction on Health Insurance Service Continuance. Journal of Financial Services Marketing 22(4): 173-186.

Abu-Salim, T., M. ElBarachi, O.P. Onyia, and M. Sujith. 2020. Effects of Smart City Service Channel- and User-Characteristics on User Satisfaction and Continuance Intention. Information Technology \& People 34(1): 147-177.

Alexander, D. 2005. Towards the Development of a Standard in Emergency Planning. Disaster Prevention and Management 14(2): $158-175$. 
AlShamsi, H., and Pathirage, C. 2015. The Role of Effective Contingency Planning in Managing Extreme Disasters in UAE, In 12th International Postgraduate Research Conference (IPGRC 2015), 10-12 June 2015, Salford Quays.

Alteneiji, H. R., Ahmed, V., and Saboor, S. 2021. A Strategic Approach to Emergency Preparedness in the UAE. In Collaboration and Integration in Construction, Engineering, Management and Technology (pp. 241-246). Springer, Cham.

Atayah, O. F., Dhiaf, M. M., Najaf, K., and Frederico, G. F. 2021. Impact of COVID-19 on Financial Performance of Logistics Firms: Evidence from G-20 Countries. Journal of Global Operations and Strategic Sourcing. 2021 Aug 11.

Azadegan, A., and K. Dooley. 2021. A Typology of Supply Network Resilience Strategies: Complex Collaborations in a Complex World. Journal of Supply Chain Management 57(1): 17-26.

Barbera, C., M. Jones, S. Korac, I. Saliterer, and I. Steccolini. 2017. Governmental Financial Resilience Under Austerity in Austria, England and Italy: How do Local Governments Cope with Financial Shocks? Public Administration 95(3): 670-697.

Belhadi, A., S. Kamble, C.J.C. Jabbour, A. Gunasekaran, N.O. Ndubisi, and M. Venkatesh. 2021. Manufacturing and service supply chain resilience to the Covid-19 outbreak: Lessons learned from the automobile and airline industries. Technological Forecasting and Social Change 163: 120447.

Bonevski, B., M. Randell, C. Paul, K. Chapman, L. Twyman, J. Bryant, I. Brozek, and C. Hughes. 2014. Reaching the Hard-to-Reach: A Systematic Review of Strategies for Improving Health and Medical Research with Socially Disadvantaged Groups. BMC Medical Research Methodology 14(1): 1-29.

Brito, J. 2007. Sending Out an S.O.S.: Public Safety Communications Interoperability as a Collective Action Problem. Federal Communications Law Journal 3: 10-17.

Cam, M.A., and V. Ramiah. 2014. The Influence of Systematic Risk Factors and Econometric Adjustments in Catastrophic Event Studies. Review of Quantitative Finance and Accounting 42(2): 171-189.

Chen, H.Y., A. Das, and D. Ivanov. 2019. Building Resilience and Managing Post-Disruption Supply Chain Recovery: Lessons from the Information and Communication Technology Industry. International Journal of Information Management 49: 330-342.

Chen, H.Y., A. Das, and D. Ivanov. 2020. A Resilience Measure for Supply Chain Systems Considering the Interruption with the Cyber-Physical Systems. Reliability Engineering \& System Safety 199: 106869.

Coppola, D. P. 2015. Hazards. Introduction to International Disaster Management, 40.

da Silveira Batista, H.M.C., G.M. Drumond, A.C. Dias, A. da Cunha Reis, and M.P. Méxas. 2019. The Influence of Technology in Logistics: An Exploratory Study. Perspectivas Contemporâneas 14(3): 108-126.

Denzin, N.K., Y.S. Lincoln, and M.D. Giardina. 2006. Disciplining Qualitative Research. International Journal of Qualitative Studies in Education 19(6): 769-782.

Dillon, B., I. Dickinson, F. Whiteford, and J. Williamson. 2009. Emergency Planning Officers' Handbook. Oxford: Oxford University Press.

Dixit, V., et al. 2020. Assessment of Pre and Post-Disaster Supply Chain Resilience Based on Network Structural Parameters with $\mathrm{CVaR}$ as a Risk Measure. International Journal of Production Economics 227: 107655.

Dolgui, A., and Ivanov, D. 2021. Ripple Effect and Supply Chain Disruption Management: New Trends and Research Directions, 102-109.

Dubai Future Foundation. 2020. Life after Covid-19, https://www.dubai future.gov.ae/wp-content/uploads/reports/DFF-Covid-19-Logis tics-ENG.pdf [Accessed on July 22, 2020]
Fahimnia, B., and A. Jabbarzadeh. 2016. Marrying Supply Chain Sustainability and Resilience: A Match Made in Heaven. Transportation Research Part e: Logistics and Transportation Review 91: 306-324.

Gerth, F., Ramiah, V., Toufaily, E., and Muschert, G. 2021. Assessing the Effectiveness of Covid-19 Financial Product Innovations in Supporting Financially Distressed Firms and Households in the UAE. Journal of Financial Services Marketing, 1-11.

Goldbeck, N. 2020. Optimal supply chain resilience with consideration of failure propagation and repair logistics. Transportation Research Part E: Logistics and Transportation Review 133: 101830.

Gopaldas, A. 2016. A Front-to-Back Guide to Writing a Qualitative Research Article. Qualitative Market Research: An International Journal. 19(1): 115-121.

Gornall, W., and I.A. Strebulaev. 2018. Financing as a Supply Chain: The capital Structure of Banks and Borrowers. Journal of Financial Economics 129(3): 510-530.

Gulfnews. 2017. UAE Rain Forces People from Homes, but No Injuries Reported. Viewed 5 July 2020, https://gulfnews.com/uae/uae-rainforces-people-from-homes-but-no-injuries-reported-1.2142716. Accessed on Nov 22, 2020.

Gulfnews. 2020a. https://gulfnews.com/uae/coronavirus-its-businessas-usual-at-uae-supermarkets-1.70570641 reported March 23, 2020. Accessed on Nov 22, 2020.

Gulfnews. 2020b. 'Covid-19: Disinfection Drive Extended to 24 hours in Dubai', viewed 1 July 2020, https://gulfnews.com/uae/gover nment/covid-19-disinfection-drive-extended-to-24-hours-indubai-1.1586019164814. Accessed on Nov 22, 2020.

Haddow, G. D., Bullock, J. A., and Coppola, D. P. 2008. Introduction to emergency management, 3rd ed., Butterworth-Heinemann homeland security series, Elsevier/Butterworth-Heinemann, viewed 10 July 2020: https://search.ebscohost.com/login.aspx?direct=true\& $\mathrm{db}=$ cat03332a\&AN=uow.b2384855\&site=eds-live.

Harrison, T., Onyia, O. P., and Tagg, S. K. 2014. Towards a Universal Model of Internet Banking Adoption: Initial Conceptualization. International Journal of Bank Marketing, 32(7).

Hasani, A., and A. Khisrojerdi. 2016. Robust Global Supply Chain Network Design Under Disruption and Uncertainty Considering Resilience Strategies: A Parallel Memetic Algorithm for a RealLife Case Study. Transportation Research Part e: Logistics and Transportation Review 87: 20-52.

Hendry, M., J. Stevenson, P. MacBryde, M. Sayed. Ball, and L. Liu. 2019. Local Food Supply Chain Resilience to Constitutional Change: The Brexit Effect. International Journal of Operations Production Management 39(3): 429-453.

Houston, J.F., C. Lin, and Z. Zhu. 2016. The Financial Implications of Supply Chain Changes. Management Science 62(9): 2520-2542.

Huang, J., W. Yang, and Y. Tu. 2020. Financing Mode Decision in a Supply Chain with Financial Constraint. International Journal of Production Economics 220: 107441.

Ivanov, D., and A. Dolgui. 2020. Viability of intertwined supply networks: extending the supply chain resilience angles towards survivability. A position paper motivated by COVID-19 outbreak. International Journal of Production Research 58(10): 2904-2915.

Ivanov, D. 2021. Lean Resilience: AURA (Active Usage of Resilience Assets) Framework for Post-Covid-19 Supply Chain Management. The International Journal of Logistics Management (in print).

Ivanov, D., and A. Dolgui. 2021. OR-methods for coping with the ripple effect in supply chains during COVID-19 pandemic: Managerial insights and research implications. International Journal of Production Economics 232: 107921.

Jing, B., and A. Seidmann. 2014. Finance Sourcing in a Supply Chain. Decision Support Systems 58: 15-20.

Kamran, R., Khan, N., and Sundarakani, B. 2021. Blockchain Technology Development and Implementation for Global Logistics 
Operations: A Reference Model Perspective. Journal of Global Operations and Strategic Sourcing. 2021 May 18.

Kouvelis, P., and W. Zhao. 2018. Who Should Finance the Supply Chain? Impact of Credit Ratings on Supply Chain Decisions. Manufacturing \& Service Operations Management 20(1): 19-35.

Kuuluvainen, A. 2012. How to Concretize Dynamic Capabilities? Theory and Examples. Journal of Strategy and Management. 5(4): 381-392.

Li, Y., C.W. Zobel, O. Seref, and D. Chatfield. 2020. Network Characteristics and Supply Chain Resilience Under Conditions of Risk Propagation. International Journal of Production Economics 223: 107529.

Liu, C.L., K.C. Shang, T.C. Lirn, K.H. Lai, and Y.V. Lun. 2018. Supply Chain Resilience, Firm Performance, and Management Policies in the Liner Shipping Industry. Transportation Research Part a: Policy and Practice 110: 202-219.

Locke, K. 2002. The Grounded Theory Approach to Qualitative Research. In Measuring and Analyzing Behavior in Organizations: Advances in Measurement and Data Analysis, ed. F. Drasgow and N. Schmitt, 17-43. Jossey-Bass.

Locke, K., Feldman, M., and Golden-Biddle, K. 2020. Coding Practices and Iterativity: Beyond Templates for Analyzing Qualitative Data. Organizational Research Methods, 1094428120948600.

Mathauer, M., and Hofmann, E. 2019. Technology Adoption by Logistics Service Providers. International Journal of Physical Distribution \& Logistics Management.

McEntire, D. A. 2015. Disaster Response and Recovery: Strategies and Tactics for Resilience, Second edition, Wiley, viewed 10 July 2020, https://search.ebscohost.com/login.aspx?direct=true\&db= cat03332a\&AN=uow.b2268209\&site=eds-live.

McKibbin, W., and D. Vines. 2020. Global Macroeconomic Cooperation in Response to the COVID-19 Pandemic: A Roadmap for the G20 and the IMF. Oxford Review of Economic Policy 36(Supplement1): S297-S337.

MEED. 2020. GCC Ramps up Covid-19 Response, Reported on March 17, 2020, viewed 22 July, 2020, https://www.meed.com/gccramps-up-covid-19-response

Mesjasz-Lech, A., and Włodarczyk, A. 2020. External Conditions of Profitability of Business Models of High-Growth Enterprises. Business Models: pp. 81-104

Mohajan, H.K. 2018. Qualitative Research Methodology in Social scIences and Related Subjects. Journal of Economic Development, Environment and People 7(1): 23-48.

Monaghan, S., J. Lavelle, and P. Gunnigle. 2017. Mapping Networks: Exploring the Utility of Social Network Analysis in Management Research and Practice. Journal of Business Research 76: 136-144.

Nia, S. P. and Kulatunga, U. 2017. The Importance of Disaster Management and Impact of Natural Disasters on Hospitals. In The 6th World Construction Symposium 2017, School of the Built Environment, Sri Lanka, 30th June-2nd July, viewed 10 July 2020, http://usir.salford.ac.uk/id/eprint/42764/.

NCEMA. 2019. National Emergency Crisis and Disaster Management Authority, Supreme National Security Council, Abu Dhabi ,viewed 9 July 2020, https://ncema.gov.ae/content/documents/ NCEMA\%20JB\%2034191\%20English.pdf.

North, J., A. Dixit, and F. Wheelahan. 2020. The Impact of Covid-19 on Supply Chains: CONSIDERATIONS for Customers and Suppliers. Governance Directions 72(4): 187-190.

Onyia, O.P., and S.K. Tagg. 2011. Effects of Demographic Factors on Bank Customers' Attitudes and Intention toward Internet Banking Adoption in a Major Developing African Country. Journal of Financial Services Marketing 16(4): 294-315.

Parsons, D. 2008. Emergency Management: Principles and Practice for Local Government. Australian Journal of Emergency Management 23(2): 75.
Perrow, C. 2007. The Next Catastrophe : Reducing our Vulnerabilities to Natural, Industrial, and Terrorist Disasters, Princeton University Press, viewed 10 July 2020, https://search.ebscohost.com/ login. asp $x$ ?direct $=$ true $\& d b=$ cat03332a $\& A N=$ uow.b $1818877 \&$ site $=$ eds-live.

Rajesh, R. 2017. Technological Capabilities and Supply Chain Resilience of Firms: A Relational Analysis Using Total Interpretive Structural Modeling (TISM). Technological Forecasting and Social Change 118: 161-169.

Remko, V. H. 2020. Research Opportunities for a More Resilient PostCovid-19 Supply Chain: +Closing the Gap Between Research Findings and Industry Practice. International Journal of Operations \& Production Management (in press).

Shah, S.K., and K.G. Corley. 2006. Building Better Theory by Bridging the Quantitative-Qualitative Divide. Journal of Management Studies 43(8): 1821-1835.

Shaluf, I.M. 2007. Disaster Types. Disaster Prevention and Management: An International Journal 16(5): 704-717.

Sharma, M. G., and Naude, M. J. 2021. Interdependence Analysis of Supplier Relationship Challenges in the South African Automotive Industry. Journal of Global Operations and Strategic Sourcing. $2021 \mathrm{Jan}$.

Shen, H., M. Fu, H. Pan, Z. Yu, and Y. Chen. 2020. The Impact of the Covid-19 Pandemic on Firm Performance. Emerging Markets Finance and Trade 56(10): 2213-2230.

Soni, V., and S. Kumar. Jain. 2014. Measuring Supply Chain Resilience Using a Deterministic Modeling Approach. Computers and Industrial Engineering 74: 11-25.

Srivastava, S., and S. Vishnani. 2021. Determinants of Mobile Bank Usage Among the bank Users in North India. Journal of Financial Service Marketing 26: 34-51.

Sundarakani, B., Ajaykumar, A., and Gunasekaran, A. 2021. Big data driven supply chain design and applications for blockchain: An action research using case study approach. Omega, 102, 102452.

Sundarakani, B., Kamran, R., Maheshwari, P., and Jain, V. 2019. Designing a Hybrid Cloud for a Supply Chain Network of Industry 4.0: A Theoretical Framework. Benchmarking: An International Journal.

Suresh, N.C., G.L. Sanders, and M.J. Braunscheidel. 2020. Business Continuity Management for Supply Chains Facing Catastrophic Events. IEEE Engineering Management Review 48(3): 129-138.

Teece, D.J., G. Pisano, and A. Shuen. 1997. Dynamic Capabilities and Strategic Management. Strategic Management Journal 18(7): 509-533.

Teece, D.J., and G. Linden. 2017. Business Models, Value Capture, and the Digital Enterprise. Journal of Organization Design 6 (1): $1-14$.

Teece, D.J. 2018. Business Models and Dynamic Capabilities. Long Range Planning 51(1): 40-49.

tradingeconomics.com (2021). United Arab Emirates - Economic Indicators. Available at: https://tradingeconomics.com/united-arabemirates/indicators [Accessed on 30 May 2021].

Twinn, I., Qureshi, N., Conde, M. L., Guinea, C. G., Rojas, D. P., Luo, J., and Gupta, H. 2020. The Impact of COVID-19 on Logistics. International Finance Corporation, Washington DC. 2020 June.

Waugh, A.L., and K. Tierney. 2007. Organizing for Emergency Management. Washington: Emergency Management Principles and Practice for Local Government.

Xu, Z., A. Elomri, L. Kerbache, and A. El Omri. 2020. Impacts of Covid-19 on Global Supply Chains: Facts and Perspectives. IEEE Engineering Management Review 48(3): 153-166.

Yin, R.K. 2003. Designing Case Studies. Qualitative Research Methods 5: 359-386.

Younis, H., Sundarakani, B., and Alsharairi, M. 2021. Applications of Artificial Intelligence and Machine Learning Within Supply 
Chains: Systematic Review and Future Research Directions. Journal of Modelling in Management.

Zhen, X., Shi, D., Li, Y., and Zhang, C. 2020. Manufacturers' Financing Strategy in a Dual-Channel Supply Chain: Third-Party Platform, Bank, and Retailer Credit Financing. Transportation Research Part E: Logistics and Transportation Review, 133, 101820.

Publisher's Note Springer Nature remains neutral with regard to jurisdictional claims in published maps and institutional affiliations.

Dr. Balan Sundarakani (B.Engg, M.Engg, $\mathrm{PhD}$ ) is an Associate Professor in the Faculty of Business and Management at the University of Wollongong (Australia) in Dubai. He has 20 years of teaching and research experience in the area of Supply Chain Management across the various universities including the National Institute of Technology (NIT), Tiruchirappalli, Indian Institute of Technology (IIT), Roorkee, Hindustan University, Chennai and the National University of Singapore (NUS), Singapore and the Chair of Logistics Management in Swiss Federal Institute of Technology (ETH), Zurich, Switzerland. So far, he has completed research and consultancy projects for the UOW Dubai, EDB Singapore, IBM, DHL, Ministry of Defence Singapore, Dubai Trade, JAFZA, and RTA Dubai. The total worth of his research and consulting projects are valued around $\mathrm{S} \$ 2$ Million plus AED 7,185,000. In March 2020, He as a Co-PI was awarded with AED 6.8 Million grant from Ministry of Education, the UAE for Food safety research in collaboration with IQBA, Dubai Municipality and UAE University. Dr. Sundarakani has published 121 research papers in the form of refereed International Journals, Book chapters and Conference Proceedings, which include; International Journal of Production Economics, Computers in Industry, Omega, Competitiveness Review, International Journal of Logistics Research and Applications, The International Journal of Logistics Management, Benchmarking: An International Journal, Journal of Quality in Maintenance Engineering, The TQM Journal etc.

Dr. Okey Peter Onyia (BA (Hons), MBA, MPhil, PGD, PG-Cert, PhD) is Associate Professor of Marketing at the Faculty of Business, Australian University of Wollongong in Dubai. His research interests focus on services marketing, online/offline financial consumer behavior, innovation diffusion, and the pedagogics of business education. His research has been published in Journal of Financial Services Marketing, International Journal of Bank Marketing, Research in Higher Education Journal, Information Technology \& People, etc. He has won a number of research awards, including "Best Paper of Conference" award at the Academic and Business Research Institute's 2012 International Conference, Las Vegas, and also "The Outstanding Paper of 2014" award by Emerald Group Publishing. 